\title{
The Review of $\mathscr{L}$ olitics
}

Published Quarterly by the University of Notre Dame, Notre Dame, Indiana.

Vol. 1

MARCH, 1939

No. 2

\section{The Pope in This World}

FOR PIUS XI praise floods the pages of all our journals. Such universal public praise, easy and flashing as some of it may be, is recognisant of the moral authority of the papacy as well as of the satisfaction of the nations in the goodness of the late Pontiff's rule. To everything so far said and done, we earnestly add our understanding of the Holy Father's achievement for the Church and for the world. In an age increasingly indifferent to and destructive of the person and of the truly communal life, he affirmed the power and justice and purpose of each and the responsibilities of the one to the other. This affirmation has ever been strong and dynamic in Catholicism. But in the last decade it became more and more impressively apparent that the Vicar of Christ, alone almost among the many leaders of men, respected the personality of man and the right significance of his life in society.

At this moment we are very much shaken. We feel that we are living in a kind of interval of history, in a duration of formlessness and fury. It appears that the "modern" civilization of the seventeenth, eighteenth and nineteenth centuries is disintegrating and a new, clear world-order has not yet been composed. Now to the Throne of Truth comes Pius XII; and it must be, under Heaven, his function to generate clarity and responsibility and purpose out of the appalling crudity of these years. Indeed we are hopeful in him and by him. In his very self, though earthly, he bears the unity of the past and present and future, of time and eternity; in his very being is the unison of religion and life, of God's world and our own. And, even in our deepest anxiety, we are confident that his hand will thwart without fear the destroyers of the personality of man and of the community of mankind, that his beneficent hand will wield and shape, in this century, a peace and a culture vital in Christ. 